\title{
Novel archetype of fluid-based energy generation system from human footsteps
}

\author{
*Mowaz Mohammed Abdul Karim ${ }^{1}$, Riyan Al Islam Reshad ${ }^{2}$, Mahmudul Haque Tomal ${ }^{1}$, Abdullah Asif \\ Khan Sazid ${ }^{1}$, Maisha Anan Prova ${ }^{3}$ \\ ${ }^{1}$ Department of Civil and Environmental Engineering, Shahjalal University of Science and Technology, Sylhet, Bangladesh \\ ${ }^{2}$ Department of Genetic Engineering and Biotechnology, Shahjalal University of Science and Technology, Sylhet, \\ Bangladesh \\ ${ }^{3}$ Department of Architecture, Shahjalal University of Science and Technology, Sylhet, Bangladesh \\ *mowaz53@student.sust.edu
}

\begin{abstract}
Increased agitation for environmental pollution, renewable energy harvesting systems have emerged as one of the key technologies globally. This work represents a novel, clean, and environmentally friendly renewable energy generation technology that harvests energy from human walking. The mechanism is based on two tiles structure paver in which a syringe is connected through unidirectional valves and mini hydro-generators that convert kinetic energy into electricity utilizing fluid movements by the flow-control mechanism. This energy harvesting mechanism can produce average output energy of 2.5J and more per step during typical human weighing 800 newton walking for $6 \mathrm{~mm}$ depression of the paver. The system is easily replicable and can be established with ease to power up lamps and emergency lighting systems etc. Compared to other energy harvesting paver systems, this system is eco-friendly and costeffective. This novel fluid-based footstep energy harvesting mechanism has substantial possibility as an effective renewable energy system for developing and developed countries.
\end{abstract}

\section{INTRODUCTION}

The global energy demand has increased by 5.2 gigajoules per capita from 2009 to 2019 thus increase in demand raised carbon dioxide emission by 4423.8 million tons in ten years ${ }^{[1]}$. Climate change due to "Enhanced Greenhouse Effect" is considered a major threat to environment. Studies have shown that carbon dioxide contributes roughly two-thirds to the effect of "enhanced greenhouse effect" ${ }^{[2]}$. It is projected that the global greenhouse gas emission will increase by $21.9 \%$ within $2050{ }^{[3]}$. According to recent studies there is consensus across recent scenario that renewable energy and energy efficiency is the most feasible direction to meet climate objectives ${ }^{[4]}$. According to the data provided by 'climate watch' heat and electricity generation of energy sector was solely responsible for more than $30 \%$ of global greenhouse gas emission in $2016^{[5,6]}$. It has become eminent to utilize renewable energy sources to reduce the effects of 'Enhanced Greenhouse Effect'. Production of energy from human locomotion is not a new idea. Various types of methods are used. Inertial energy harvesting being one of them. Kornbluh et al. ${ }^{[7]}$ designed a shoe to harvest inertial energy using dielectric elastomer. In their experiments, they obtained a maximum output energy of $0.8 \mathrm{~J}$. Gorlatova et al. ${ }^{[8]}$ designed numerous energy harvesting wireless devices placed around different parts of human body. These devices produced varying amount of energy from 155 $\mu \mathrm{W}$ to $202 \mu \mathrm{W}$. On two separate occasions, experiments done by Huang et al. ${ }^{[9]} \&$ Buren et al. ${ }^{[10]}$ for inertial energy harvesting, they got around $100-200 \mu \mathrm{W}$ of maximum energy output.

Piezoelectricity is another method to harvest energy from human locomotion. Antaki et al. ${ }^{[11]}$ designed a shoe with piezoelectric array within the midsole area for conversion of mechanical energy into electrical energy. Their experimental results show that 676$2100 \mathrm{~mW}$ of electricity can be produced by jogging. Qian et al. ${ }^{[12]}$ designed a piezoelectric boot energy harvester. Experimental results show 8.5-9.3 $\mathrm{mW}$ of energy can be generated with a average speed of walking. Roundy et al. ${ }^{[13]}$ designed a piezoelectric vibration based generator. Their experimental results show a maximum of $375 \mu \mathrm{W}$ energy production. Wen et al. ${ }^{[14]}$ designed a multi-stage force amplification frame piezoelectric energy harvester, which can harvest $50.8 \mathrm{~mW}$ of energy. Kymissis et al. ${ }^{[15]}$ designed devices capable of "parasitically" harvesting energy from shoes while walking. Their experiments show that their Polyvinylidinefluoride stave generation can produce $1.1 \mathrm{~mW}$ of energy.

Another approach for harvesting energy from human locomotion is electromagnetic based energy harvesting system. Donelan et al. ${ }^{[16]}$ designed a biomechanical knee brace energy harvester. Their experiments demonstrated that $4.8 \pm 0.8 \mathrm{~W}$ of energy can be harvested, while requiring little extra effort from the user. Taliyan et al. ${ }^{[17]}$ designed a footstep energy harvesting device using dc generator. Their experimental results show that 3-5J of energy can be produced with each step. Liu et al. ${ }^{[18]}$ designed an energy harvesting paver which experimentally harvests $1.8 \mathrm{~J}$ of energy per step. Ang et al. ${ }^{[19]}$ designed a footstep power generator from kinetic energy capable of generating $0.2900 \mathrm{~W}$ of energy, shown from experimental results. Dibin et al. ${ }^{[20]}$ designed an in-shoe energy harvester. Their experimental results show that $55.6 \mu \mathrm{J}$ of energy per step can be generated. Romero et al. ${ }^{[21]}$ designed a device which generates energy from body motion to power biomedical devices. From their experiments, $2.35 \mu \mathrm{W}$ of energy 
can be generated by this device. Even though generated energy from human locomotion is quite low there are still opportunities to improve overall efficiency. There are some existing ways to harvest energy from footsteps, some of which are still being developed \& some have been commercialized already. One of them are, Pavegen, ${ }^{[23]}$ it is already available in the market. It produces $5 \mathrm{~W}$ of energy from continuous steps \& is made from recycled items. But it is expensive, not suitable for low population density area \& leaves carbon footprints. Another devise is Piezoelectric tiles, designed by Boby et al. ${ }^{[24]}$ which is easily replaceable \& low maintenance. But it is also easily damaged, highly temperature sensitive. In-shoe energy harvester ${ }^{[25,26]}$ on the other hand is comfortable, cheaper, portable \& provides sufficient amount of energy. Some disadvantages of this are limited application of the harvested energy \& exposure to foreign factors such as water $\&$ mud. Liu et al. ${ }^{[18]}$ designed energy harvesting paver can be easily constructed \& provide with good energy output but needs more maintenance \& may not be comfortable for the user. Heel strike-induced airflow footstep energy harvester designed by Fu et al. ${ }^{[27]}$ can be easily constructed \& replaced but has a low energy output $\&$ is not suitable for low population density area. Mamun et al. ${ }^{[28]}$ designed a footstep energy harvesting system using hydro-generator has sufficient power output \& can be constructed with cheap, locally available materials. As it has moving parts, it'll need more maintenance, can be damaged due to improper use $\&$ not suitable for low population density area. This work represents a novel fluid based energy harvesting paver from human footsteps. In this paper a fluid flow simulation, numerical simulation and experimental data has been introduced.

\section{IDEA CONCEPT}

Study of biomechanics shows the direction of force exerted on ground has a vertical and horizontal component and has peak vertical component once per cycle ${ }^{[29]}$. Peak vertical force exerted to the ground by walking and running ranges between $M g-3 M g$ ${ }^{[30]}$. The design concept of our mechanism intends to utilize the peak vertical force generated by walking or running and converting the force into electrical energy using principles of fluid mechanics. A single unit of the design consists of a syringe with two pathways connected to unidirectional valves, a mini water turbine generator and a separate water chamber. The plunger of the syringe is covered and fixed to a top plate which receives the vertical force and pushes the plunger to exert fluid through a unidirectional valve and rotate the turbine of the generator. After releasing force from the top plate, helical springs connected to each corner pushes the top plate to its initial position along with the plunger. The latter process creates a negative pressure inside the syringe and activates the other check valve which allows water from a small chamber to refill the syringe. The whole process acts simultaneously. An isometric view of the whole design is shown in Fig. 1. The power generated from the footsteps is stored in capacitors instantly and released to a charge controller which limits the charge flow for charging battery at a safer rate. The flowchart is shown in Fig. 2. To collect maximum output from the whole system the design of water turbine generator consists of a stator and a rotor comprised of pelton wheel and permanent magnet.

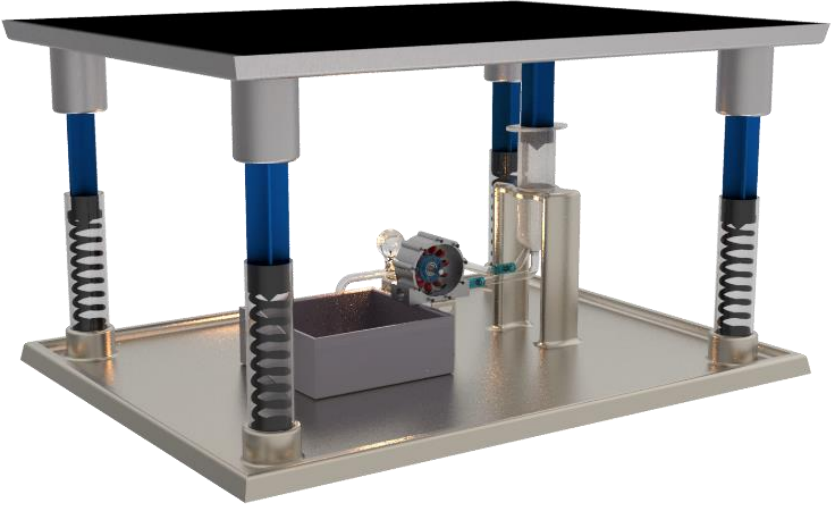

Fig. 1

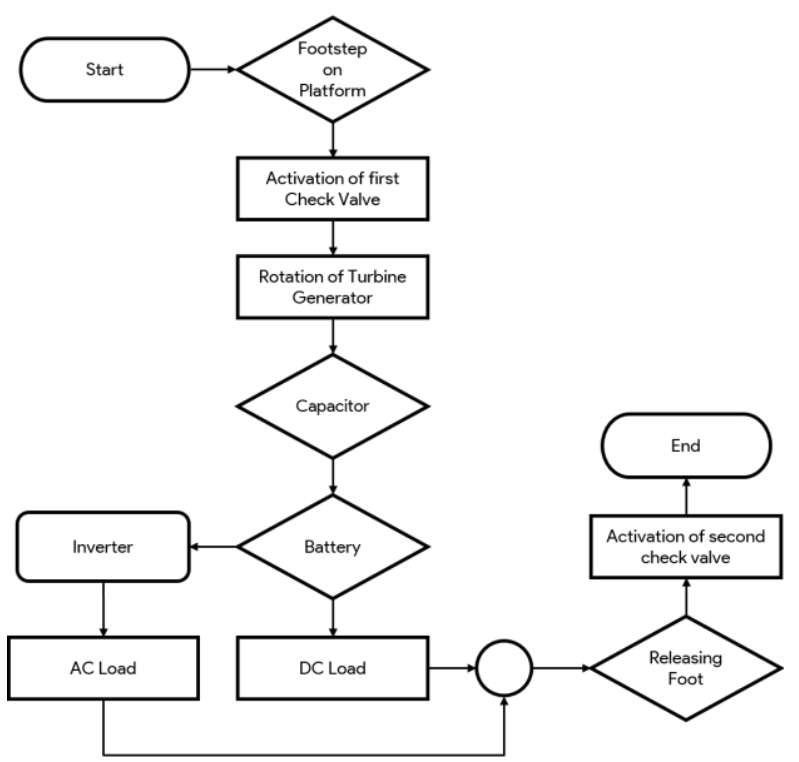

Fig. 2

\section{MATHEMATICAL CALCULATION}

The flow inside a pipe is considered laminar flow according to Reynolds number. Let the force one the plunger be $F$ and $A_{s}, A_{n}$ be the cross-sectional area of the syringe and nozzle respectively. The force on the plunger adds pressure $p_{1}=\frac{F}{A_{S}}$ inside the syringe. Applying Bernoulli's equation for the syringe,

$$
p_{0}+\frac{p_{1}}{\rho g}+\frac{v_{s}^{2}}{2 g}=p_{0}+\frac{v_{n}^{2}}{2 g}
$$

Where $v_{s}$ is the velocity of flow inside the syringe and $v_{n}$ is the velocity inside the nozzle. The velocities are related via continuity equation:

$$
A_{s} \times v_{s}=A_{n} \times v_{n}
$$

So calculating the velocity through the nozzle, we have,

$$
\frac{F}{A_{s} \rho g}+\left\{\frac{1}{2 g} \times\left(\frac{A_{n} v_{n}}{A_{s}}\right)^{2}\right\}=\frac{v_{n}^{2}}{2 g}
$$




$$
v_{n}^{2}\left(1-\frac{A_{n}^{2}}{A_{s}^{2}}\right)=\frac{2 F}{A_{s} \rho}
$$

The hydropower from the nozzle will be,

$$
P=\frac{\left(A_{n} v_{n}\right) \times \rho g \times \frac{v_{n}^{2}}{2 g}}{1000} K W
$$

The major loss from the system can be frictional head loss which can be calculated using Darcy's equation.

$$
h_{l}=\frac{f L v^{2}}{2 g D}
$$

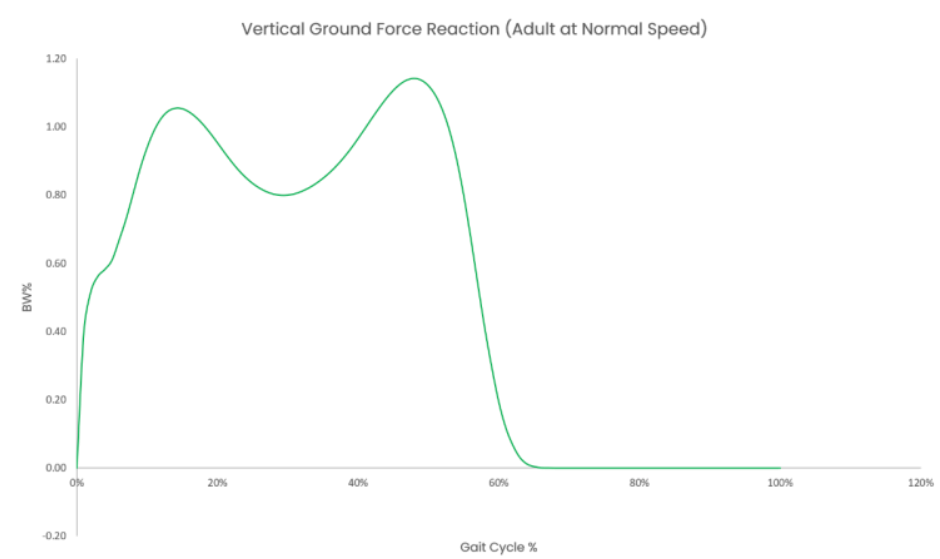

Fig. 3 Vertical Ground Reaction Force of an adult walking at normal speed ${ }^{[31]}$

\section{MATERIALS AND METHODS}

\subsection{FLUID FLOW SIMULATION}

Mathematical modelling shows that generation of power mostly depends on velocity of fluid from nozzle and the area of the nozzle. The highest possible value of $v_{n}$ depends on low area of the syringe and low difference between $A_{n}$ and $A_{s}$. However, high power does not necessarily mean high energy. ANSYS CFD software was used to see how the velocity and pressure inside a syringe was influenced by applying load on the piston of the syringe Fig.6-10. As per simulations, it can be said pressure inside the syringe remains maximum and the minimum value can be observed at the end of the nozzle.

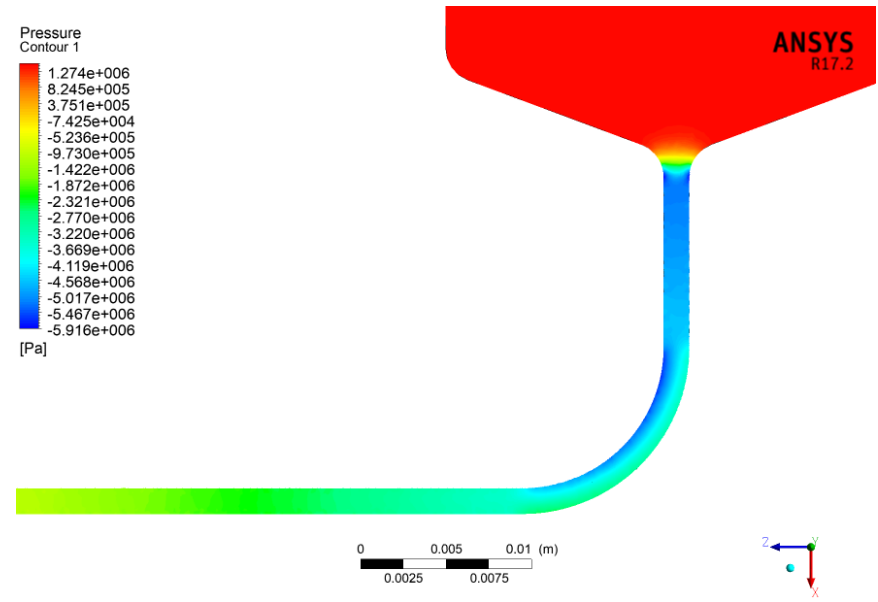

Fig.4 Syringe Diameter 27mm; Nozzle Diameter $1.5 \mathrm{~mm}$
The velocity of the fluid inside the syringe works disproportionately to the pressure of the fluid. As it shows the velocity can be found maximum at the end of the nozzle and minimum inside the barrel.
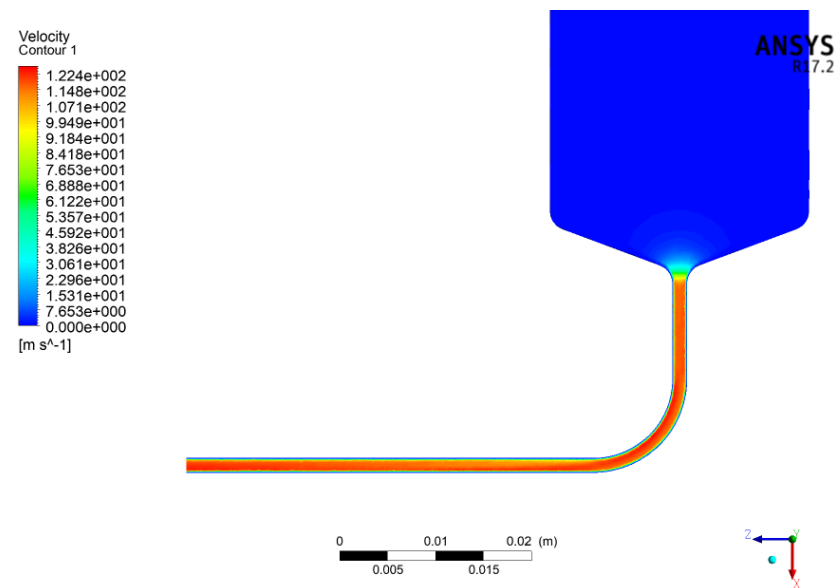

Fig.5 Syringe Diameter 27mm; Nozzle Diameter $1.5 \mathrm{~mm}$
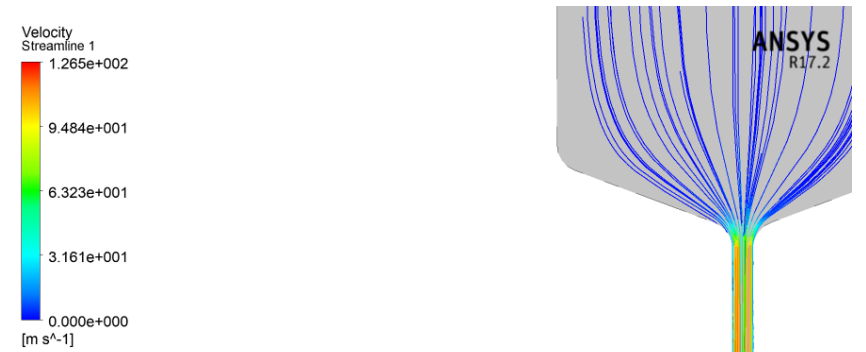

Fig.6 Syringe Diameter 27mm; Nozzle Diameter $1.5 \mathrm{~mm}$

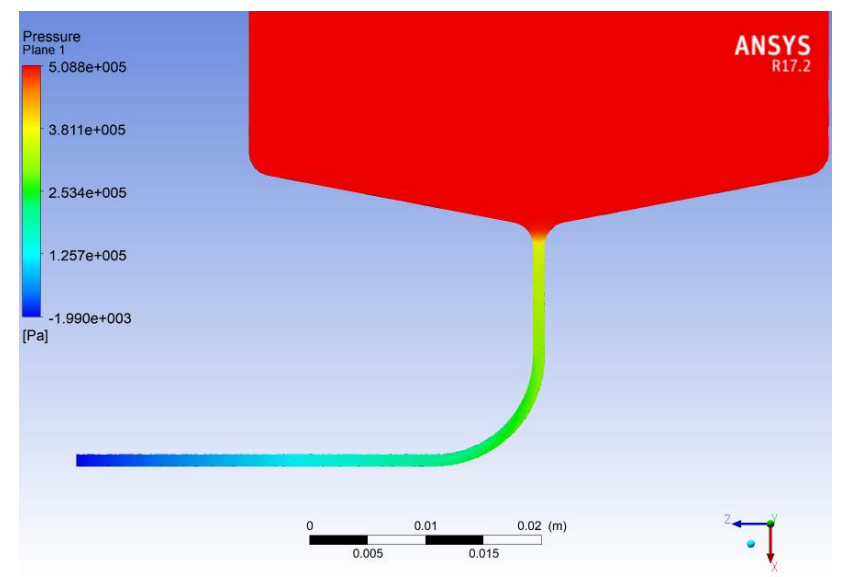

Fig.7 Syringe Diameter 50mm; Nozzle Diameter 1.mm 


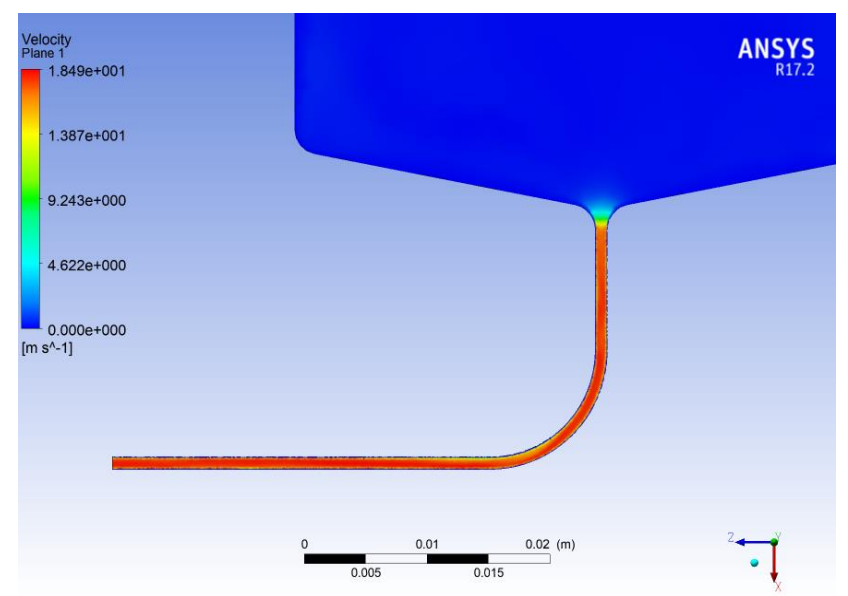

Fig.8 Syringe Diameter 50mm; Nozzle Diameter 1.mm

\subsection{PROTOTYPE EXPERIMENTATION}

The prototype of the mechanism was developed using low-cost timber, a $50 \mathrm{ml}$ syringe with barrel and nozzle diameter of $27 \mathrm{~mm}$ and $1.5 \mathrm{~mm}$ respectively, 4 helical springs, a f polyvinyl chloride (PVC) tube of $1.5 \mathrm{~mm}$ inner diameter and 2 one-way check valves. The experiment was conducted using a subject of 50-kilogram mass applying load on the top plate with depression of $6 \mathrm{~mm}$ according to the allowed standards of Americans with Disabilities Act (ADA) ${ }^{[32]}$ Fig.9-10.

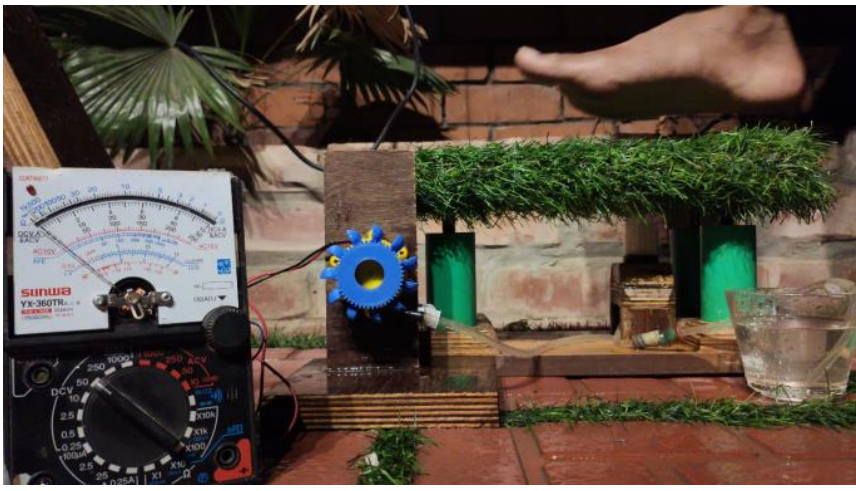

Fig.9 Syringe Diameter 27mm; Nozzle Diameter $1.5 \mathrm{~mm}$

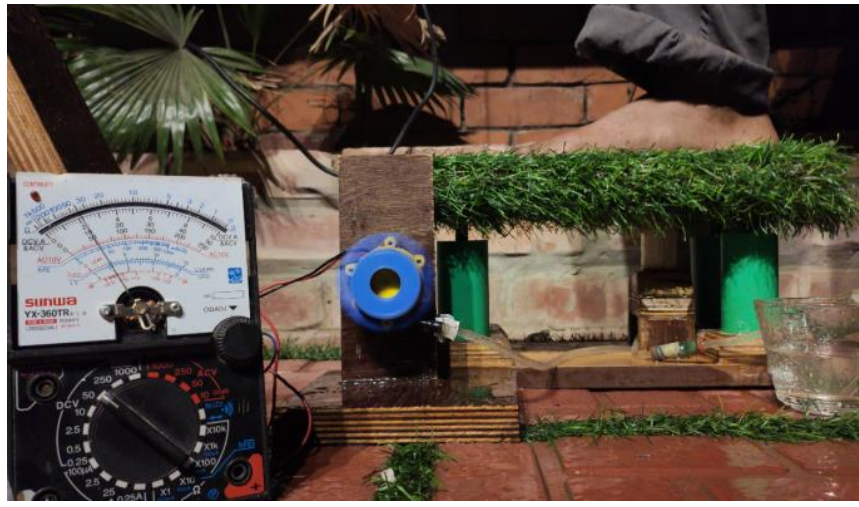

Fig.10 Syringe Diameter 27mm; Nozzle Diameter $1.5 \mathrm{~mm}$
A mini water turbine generator with capacity to generate maximum 12 volts and 10 watts of power was used in the experiment.

\section{RESULTS}

To verify the output power of the energy harvesting mechanism, we tested it using a multimeter. It turns out that the mechanism can generate peak 12 volts and 10 watts of power for this specific type of generator at its specified conditions from a subject weighing 490 N. However, the maximum amount of energy that can be generated in our system could not be tested due to the limited capacity of our water turbine generator. The result is shown in Fig.10. Our mathematical analysis can predict the maximum outcome in this mechanism. Commercially available syringes with barrel diameter and nozzle diameter of $27 \mathrm{~mm}$ and $1.5 \mathrm{~mm}$ can generate around 2.5 Joules from a subject weighing $800 \mathrm{~N}$ while walking at normal speed. Analysis in Fig.11 shows the approximate energy that can be generated utilizing velocity jet from the syringes without considering any losses for turbine generators based on the VGRF data from the work of Bovi et al. ${ }^{[31]}$. The analysis was done by feeding the VGRF data to our mathematical model.

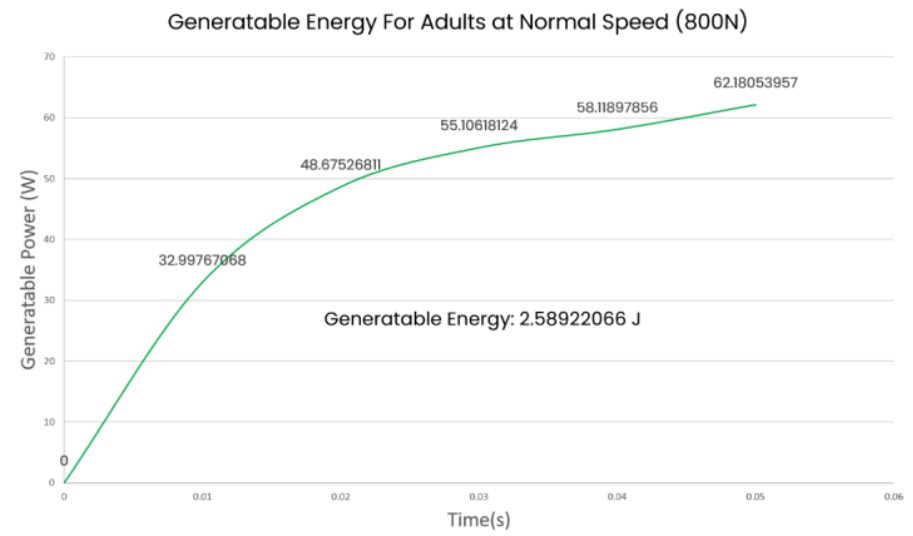

Fig. 11 Vertical Ground Reaction Force of an adult weighing $800 \mathrm{~N}$ walking at normal speed for a barrel diameter and nozzle diameter of $27 \mathrm{~mm}$ and $1.5 \mathrm{~mm}$, respectively.

The standard syringe of the mentioned diameters cannot utilize full potential of the syringe and peak force generated from walking. Thus, the system requires an optimum syringe design to utilize the peak powers to generate highest energy.

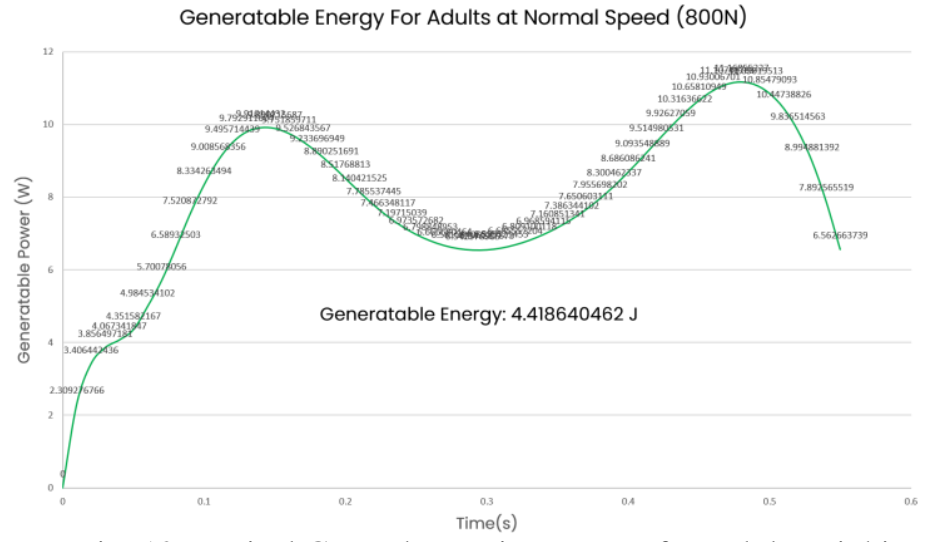

Fig. 12 Vertical Ground Reaction Force of an adult weighing walking at normal speed for a barrel diameter and nozzle diameter of $50 \mathrm{~mm}$ and $1 \mathrm{~mm}$, respectively. 
The syringe with the barrel diameter and nozzle diameter of $50 \mathrm{~mm}$ and $1 \mathrm{~mm}$, respectively can utilize peak power and has the potential to generate highest energy for displacement of $6 \mathrm{~mm}$.

\section{DISCUSSION}

As review represented in the paper, this work has the capability to produce higher energy output compared to most of the outputs mentioned in other literatures. Most of the previous work shows the maximum output power from the generators. However, high output power does not necessarily indicate higher energy generation. Liu et al. ${ }^{[18]}$ showed their novel paver has the capacity to generate 1.8 Joules of energy from a person weighing $800 \mathrm{~N}$. The biomechanical knee brace energy harvester designed by Donelan et al. ${ }^{[16]}$ shows that they can generate electricity at $4.8 \pm 0.8$ $\mathrm{W}$ of power. The in-shoe energy harvester designed by Dibin et al. ${ }^{[20]}$ can generate $55.6 \mu \mathrm{J}$ of energy per step. Our analysis indicates our system has the capacity to generate 2.58 Joules of energy from a subject weighing $800 \mathrm{~N}$. The generated energy can reach up to 4.4 Joules depending on the design of the syringe. However, the analysis does not consider any system loss. In our analysis, we neglected losses of head due to sudden contraction and losses of head due to bends and elbow. Which can be countered with proper designing of the syringe and connections. Maximum possible efficiency of pelton wheel impulse turbine can reach up to $95 \%$, and even in micro scales the turbine generator can reach $90 \%$ efficiency ${ }^{[33]}$. It can be a prospective solution for energy harvesting paver system that can generate high amounts of energy compared to most works in this field. Considering all the facts our mechanism exceeds most of the works in other literatures.

\section{CONCLUSION}

In this research we presented design, analysis, modeling, simulations and experiments of a novel fluid-based energy harvesting system. The novel mechanism has the potential to utilize energy with high efficiency compared to other mechanisms from human walking. Despite all optimizations there can be no prime design that can utilize maximum output from every subject while walking, fast walking or running. The condition varies from weight and other parameters of a subject. Based on the simulations the syringe with measurements of $50 \mathrm{~mm}$ and $1 \mathrm{~mm}$ of barrel and nozzle respectively can be considered as the optimum design for maximum cases. The simulations show it has the input energy of 4.4 $\mathrm{J}$ approximately which is significantly higher than maximum literatures. In the prototype design we excluded two extremely important parts. To make the system more sustainable the turbine generator requires a covering and a pathway to recycle the water usage. It is also very important to build a closed system to avoid evaporation loss for commercial usage. Thus, this novel mechanism has promising prospective as renewable high efficiency energy harvesting paver.

\section{REFERENCE:}

[1] "Statistical review of world energy (2020)" Retrieved 14

October 2020
[2] Jain, P. C. (1993). Greenhouse effect an climate change:

Scientific basis and overview.Renewable Energy, 3(4), 403-420. https://doi.org/10.1016/0960-1481(93)90108-S

[3] Projected CO2 emissions worldwide 2050. (n.d.). Statista.

Retrieved January 12, 2021, from

https://www.statista.com/statistics/263980/forecast-of-global-

carbon-dioxide-emissions/

[4] Gielen, D., Boshell, F., Saygin, D., Bazilian, M. D., Wagner, N., \& Gorini, R. (2019). The role of renewable energy in the global energy transformation. Energy Strategy Reviews, 24, 38-

50. https://doi.org/10.1016/j.esr.2019.01.006

[5] Climate Watch. (n.d.). Retrieved January 12, 2021, from https://www.climatewatchdata.org/ghg$\underline{\text { emissions?breakBy=sector\&calculation }=\text { ABSOLUTE_VALUE \& }}$ chartType=percentage \&end_year $=2016 \&$ sectors $=$ building $\% 2 \mathrm{Cel}$ ectricity-heat $\% 2 \mathrm{Cfugitive-emissions} \% 2 \mathrm{Cmanufacturing}$ -

construction $\% 2$ Cother-fuel-

$\underline{\text { combustion\%2Ctransportation\&start_year }=1990}$

[6] 4 Charts Explain Greenhouse Gas Emissions by Countries

and Sectors $\mid$ World Resources Institute. (n.d.). Retrieved January

12, 2021, from https://www.wri.org/blog/2020/02/greenhouse-

gas-emissions-by-country-sector

[7] Kornbluh, R. D., Pelrine, R., Pei, Q., Heydt, R., Stanford, S., Oh, S., \& Eckerle, J. (2002). Electroelastomers: Applications of dielectric elastomer transducers for actuation, generation, and smart structures. Smart Structures and Materials 2002: Industrial and Commercial Applications of Smart Structures Technologies, 4698, 254-270. https://doi.org/10.1117/12.475072

[8] Gorlatova, M., Sarik, J., Grebla, G., Cong, M., Kymissis, I., \& Zussman, G. (2015). Movers and Shakers: Kinetic Energy 
Harvesting for the Internet of Things. IEEE Journal on Selected

Areas in Communications, 33(8), 1624-1639.

https://doi.org/10.1109/JSAC.2015.2391690

[9] Huang, H., Merrett, G. V., \& White, N. M. (2011). Human-

powered inertial energy harvesters: The effect of orientation,

location and activity on obtainable power. Procedia Engineering,

25, 815-818. https://doi.org/10.1016/j.proeng.2011.12.200

[10] Buren, T. von, Mitcheson, P. D., Green, T. C., Yeatman, E.

M., Holmes, A. S., \& Troster, G. (2006). Optimization of inertial micropower Generators for human walking motion. IEEE

Sensors Journal, 6(1), 28-38.

https://doi.org/10.1109/JSEN.2005.853595

[11] Antaki, J. F., Bertocci, G. E., Green, E. C., Nadeem, A., Rintoul, T., Kormos, R. L., \& Griffith, B. P. (1995). A gaitpowered autologous battery charging system for artificial organs. ASAIO Journal (American Society for Artificial Internal Organs: 1992), 41(3), M588-595. https://doi.org/10.1097/00002480$\underline{199507000-00079}$

[12] Qian, F., Xu, T.-B., \& Zuo, L. (2019). Material equivalence, modeling and experimental validation of a piezoelectric boot energy harvester. Smart Materials and Structures, 28(7), 075018. https://doi.org/10.1088/1361-665X/ab1eb7

[13] Roundy, S., \& Wright, P. K. (2004). A piezoelectric vibration based generator for wireless electronics. Smart Materials and Structures, 13(5), 1131-1142. https://doi.org/10.1088/0964-1726/13/5/018

[14] Wen, S., \& Xu, Q. (2019). Design of a Novel Piezoelectric Energy Harvester Based on Integrated Multistage Force Amplification Frame. IEEE/ASME Transactions on
Mechatronics, 24(3), 1228-1237.

https://doi.org/10.1109/TMECH.2019.2906999

[15] Kymissis, J., Kendall, C., Paradiso, J., \& Gershenfeld, N. (1998). Parasitic power harvesting in shoes. Digest of Papers. Second International Symposium on Wearable Computers (Cat. No.98EX215), 132-139.

https://doi.org/10.1109/ISWC.1998.729539

[16] Donelan, J. M., Naing, V., \& Li, Q. (2009). Biomechanical energy harvesting. 2009 IEEE Radio and Wireless Symposium, 1-4. https://doi.org/10.1109/RWS.2009.4957269

[17] Taliyan, S. S., Biswas, B. B., Patil, R. K., \& Srivastava, G.

P. (2010). Electricity From Footsteps. 313, 4.

[18] Liu, M., Lin, R., Zhou, S., Yu, Y., Ishida, A., McGrath, M., Kennedy, B., Hajj, M., \& Zuo, L. (2018). Design, simulation and experiment of a novel high efficiency energy harvesting paver. Applied Energy, 212, 966-975.

https://doi.org/10.1016/j.apenergy.2017.12.123

[19] Ang, C. K., Al-Talib, A. A., Tai, S. M., \& Lim, W. H.

(2019). Development of a footstep power generator in converting kinetic energy to electricity. E3S Web of Conferences, 80, 02001. https://doi.org/10.1051/e3sconf/20198002001

[20] An electromagnetic in-shoe energy harvester using wave springs-IEEE Conference Publication. (n.d.). Retrieved January 15,2021 , from

https://ieeexplore.ieee.org/abstract/document/8390785

[21] Romero, E., Warrington, R. O., \& Neuman, M. R. (2009). Body motion for powering biomedical devices. 2009 Annual International Conference of the IEEE Engineering in Medicine 
and Biology Society, 2752-2755.

https://doi.org/10.1109/IEMBS.2009.5333329

[22] Chand, A. A., Shamsul Arefin, A. S. M., Islam, F. R., Prasad, K. A., Singh, S., Cirrincione, M., \& Mamun, K. A. (2020). Design simulation of a novel fluid based footstep energy harvesting system. Sustainable Energy Technologies and Assessments, 39, 100708.

https://doi.org/10.1016/j.seta.2020.100708

[23] Seow, Z. L., Chen, S. T., \& Khairudin, N. B. (2011). An investigation into energy generating tiles: Pavegen. https://doi.org/10.14288/1.0108425

[24] Boby, K. (2014). Footstep Power Generation Using Piezo Electric Transducers. 3(10), 4.

[25] Choi, Y.-M., Lee, M. G., \& Jeon, Y. (2017). Wearable Biomechanical Energy Harvesting Technologies. Energies, 10(10), 1483. https://doi.org/10.3390/en10101483

[26] Xie, L., \& Cai, M. (2015). An In-Shoe Harvester With Motion Magnification for Scavenging Energy From Human Foot Strike. IEEE/ASME Transactions on Mechatronics, 20(6), 32643268. https://doi.org/10.1109/TMECH.2015.2428618

[27] Fu, H., Cao, K., Xu, R., Bhouri, M. A., Martinez-Botas, R., Kim, S.-G., \& Yeatman, E. M. (2016, July 21). Footstep energy harvesting using heel strike-induced airflow for human activity sensing. 13th IEEE International Conference on Wearable and Implantable Body Sensor Networks (BSN).

https://doi.org/10.1109/BSN.2016.7516245

[28] Mamun, K., Islam, F. M. R., Cirrincione, M., Chandra, S. P., $\&$ Deo, R. N. (2018). Foot steps waste energy harvesting system using hydro generator [Other]. IP Australia.
http://pericles.ipaustralia.gov.au/ols/auspat/applicationDetails.do? applicationNo $=2018100812$

[29] Zajac, F. E., Neptune, R. R., \& Kautz, S. A. (2003).

Biomechanics and muscle coordination of human walking: Part

II: Lessons from dynamical simulations and clinical implications.

Gait \& Posture, 17(1), 1-17. https://doi.org/10.1016/S0966$\underline{6362(02) 00069-3}$

[30] Cross, R. (1999). Standing, walking, running, and jumping on a force plate. American Journal of Physics, 67(4), 304-309.

https://doi.org/10.1119/1.19253

[31] Bovi, G., Rabuffetti, M., Mazzoleni, P., \& Ferrarin, M. (2011). A multiple-task gait analysis approach: Kinematic, kinetic and EMG reference data for healthy young and adult subjects. Gait \& Posture, 33(1), 6-13.

https://doi.org/10.1016/j.gaitpost.2010.08.009

[32] https://www.access-board.gov/ada/

[33] Pelton and turgo turbines-Renewables First. (n.d.).

Renewables First - The Hydro and Wind Company. Retrieved June 22, 2021, from

https://www.renewablesfirst.co.uk/hydropower/hydropowerlearning-centre/pelton-and-turgo-turbines/ 